\title{
AgOSTINHO, ANSELMO E KILWARDBY SOBRE A LINGUAGEM MENTAL*
}

José Filipe Silva

Universidade de Jyväskylä, Finlândia

Num estudo anterior tive ocasião de analisar com algum detalhe a solução do Dominicano Roberto Kilwardby (1215?-1279) ${ }^{1}$ relativamente ao problema da distinção das pessoas na Trindade divina, tal como formulada nas questões 35 e 36 do primeiro livro das suas Questões sobre o livro das Sentenças de Pedro Lombardo ${ }^{2}$. Numa espécie de continuação desse estudo, gostaria de, no presente texto, analisar de que modo o critério de distinção pessoal que Kilwardby defende nesses textos se aplica às faculdades da alma racional.

Partindo da origem como causa da distinção pessoal, Kilwardby considera, seguindo as pisadas de Agostinho e Anselmo, de que modo a relação entre gerar e ser gerado se encontram no processo de pensar. $\mathrm{Na}$ primeira secção abordarei o modo como as faculdades da alma racional humana são a imagem da trindade divina, aplicando-se às faculdades o mesmo critério de distinção que se aplicam às pessoas divinas. Kilwardby encontra algumas dificuldades em lidar com a interpretação psicológica de Anselmo de Cantuária. De seguida analisar-se-ão os dois modelos do pensamento propostos por Agostinho no De Trinitate: o pensamento como visão (isto é, se videre é o mesmo que intelligere) e o pensamento como discurso (isto é, se dicere é o mesmo que intelligere). Na segunda

\footnotetext{
* A minha participação no Colóquio que motivou a realização deste artigo apenas foi possível pelo financiamento do Gabinete de Filosofia Medieval da Universidade do Porto.

1 Para uma apresentação da vida e obra de Kilwardby, ver o meu "Robert Kilwardby" in Encyclopedia of Medieval Philosophy. Dordrecht (forthcoming). Um estudo detalhado da sua vida pode ser encontrado em Sommer-Seckendorff, E.M.F., Studies in the Life of Robert Kilwardby, O.P. Roma, 1937.

2 "A simplicidade divina na teologia de Roberto Kilwardby", in M.L. Xavier (ed), A questão de Deus na História da Filosofia. Lisboa, 2008, pp. 515-525.
}

Philosophica, 34, Lisboa, 2009, pp. 157-179 
parte do meu texto centro-me sobre este último aspecto - o modelo linguístico do pensamento - enquanto que na terceira parte me ocuparei do modelo visual do pensamento. Gostaria de terminar esta introdução deixando claro que o meu uso de Agostinho e Anselmo é instrumental, visto que me interessa discutir de que modo as suas teses são entendidas e utilizadas por Kilwardby e não se Kilwardby é ou não, nem em que medida, fiel ao pensamento original destes autores. Talvez esta nota não seja necessária, mas é talvez importante para qualificar o tipo de abordagem adoptada.

\section{Trindade divina e razão humana}

Na questão 36 (QLIS)3 ${ }^{3}$, Kilwardby começa por salientar a importância da posição de Ricardo de S. Victor na discussão do problema da Trindade. Contudo, Kilwardby considera que Ricardo sublinha o carácter comum da essência mas não fornece argumentos suficientes para a distinção pessoal. Kilwardby continua encontrando na diferença de origem, isto é, no modo de originar/ter origem a explicação para a pluralidade de pessoas no seio da Trindade divina. De seguida, Kilwardby introduz a discussão das faculdades da alma racional como imagem da Trindade. É nesta analogia da Trindade com a psicologia humana que me vou centrar. O seu objectivo principal é encontrar uma fórmula que, aplicando-se às pessoas e à essência divina, se aplique de igual modo às faculdades. Tal é possível porque as premissas são de facto as mesmas: a distinção das pessoas não provoca nenhuma fractura na essência divina, do mesmo modo que a distinção entre faculdades não afecta a simplicidade da alma racional.

3 As obras de Kilwardby são citadas segundo o seguinte sistema de referências: Commentary on the Liber Sex Principiorum (LSP), ed. P.O. Lewry, Robert Kilwardby's Writings on the Logica Vetus Studied with Regard to their Teaching and Method. Unpublished Ph.D. Dissertation. Oxford, 1978, pp. 390-407; De Spiritu Fantastico (DSF), ed. P.O. Lewry. Oxford, 1987; De tempore (DT), ed. P.O. Lewry. Oxford, 1987. (Ambas as obras foram traduzidas por A. Broadie in Robert Kilwardby O.P., On Time and Imagination. Oxford, 1993.) De ortu scientiarum (DOS), ed. Judy. Oxford, 1976; Quaestiones in Librum Primum Sententiarum (QLIS), ed. J. Schneider. Munique, 1986; Quaestiones in Librum Secundum Sententiarum (QLIIS), ed. G. Leibold. Munique, 1992; Quaestiones in Librum Tertium Sententiarum, Teil 1: Christologie (QLIII1S), ed. E. Gössmann. Munique, 1982; Quaestiones in Librum Tertium Sententiarum, Teil 2: Tugendlehre (QLIII2S), ed. G. Leibold. Munique, 1985; De 43 questionibus (D43Q), ed. H.-F. Dondaine, "Le "de 43 questionibus" de Robert Kilwardby", Archivium Fratrum Praedicatorum 47 (1977), 5-50; Epistola ad Petrum de Confleto Archiepiscopum Corinthi (E), F. K. Ehrle, ed., Gesammelte Aufsätze zur Englischen Scholastik. Roma, 1970. Sigo o seguinte modelo de citação: abreviatura da obra, número da página.linhas. 
Para Kilwardby, as pessoas distinguem-se através da geração ${ }^{4}$, isto é, pelas propriedades mutuamente exclusivas que decorrem das diferentes relações de geração e procedência: o Pai gera, o Filho é gerado e gera, o Espírito Santo procede 5 . (Ou, as propriedades de generatio (Pai), nativitas (Filho), spiratio (Espírito Santo)) $)^{6}$. Mas uma vez esclarecida a causa da distinção e as propriedades de cada pessoa, Kilwardby procede para a análise da identificação da pessoa do Filho com o verbum, no contexto da alma racional como imagem da trindade divina. E é nesse contexto que a analogia do pensar como ver e do pensar como falar tem lugar.

A este propósito, Kilwardby entende existir um certo confronto entre a proposta Anselmiana e Augustiniana. De facto, Kilwardby considera que o modo de distinção proposta por Anselmo promove (ou pelo menos permite) a confusão entre as pessoas e a essência divina - e assim entre as faculdades e a forma substancial a que pertencem - ao não distinguir de modo suficiente as propriedades específicas de cada pessoa ${ }^{7}$. De outro modo, o problema reside no facto de Anselmo confundir entre aquilo que é dito de cada pessoa, constituindo a sua propriedade pessoal distintiva (e por isso definidora), e aquilo que é dito da essência. Ao esclarecer de que modo as propriedades devem ser ditas da pessoa de modo próprio e da essência de modo acidental, Kilwardby acredita ter resolvido o problema criado, aos seus olhos, por Anselmo.

Anselmo, seguindo a equivalência proposta por Agostinho, defende no capítulo 59 do Monologion (M), que a faculdade da memória na alma racional humana corresponde à pessoa do Pai na Trindade divina, a faculdade da inteligência à pessoa do Filho, o amor à pessoa do Espírito Santo $^{8}$. Mas Anselmo vê nesta identificação um possível problema: se cada uma das pessoas está restringida a uma certa operação, então, como se pode afirmar a omnipotência do Pai, ou do Filho? - isto é, a identificação de uma pessoa com uma faculdade e com uma operação que pertence

4 "Item sola causa pluralitatis personarum in Deo est quod Deus de Deo nascendo et procedendo", QLIS 36, 93.17-8. Ver também QLIS 36, 94.36-40.

5 "Declarata est igitur tota propositio scilicet quod tantum unica potest esse persona ex se habens esse divinum et alteri tribuens, et una sola recipiens solum et nulli tribuens, et una sola media recipiens et tribuens", QLIS 36, 98.194-6. Para os detalhes desta solução, ver o meu "A simplicidade divina na teologia de Roberto Kilwardby", in M.L. Xavier (ed), A questão de Deus na História da Filosofia. Lisboa, 2008, pp. 515-525.

${ }^{6}$ QLIS 36, 119.860-3.

7 Isto mesmo é notado por Tomás de Aquino (cf ST I, q.34, a.1, ad 2). Ver G. Emery, La théologie trinitaire de saint Thomas d'Aquin. Paris, 2004, pp. 224-5.

${ }^{8}$ QLIS 36, 99.203-8. Cf. Anselmo de Cantuária, Monologion, ed. F. S. Schmitt, in Opera omnia, I. Edinburgh: Thomas Nelson, 1946, p. 70: "Intelligitur autem in memoria pater, in intelligentia filius, in amore utriusque spiritus". 
de modo essencial a essa pessoa, em exclusividade, parece implicar que apenas uma determinada pessoa é capaz de realizar uma determinada operação. Ora, tal concepção impõe um limite ao poder que deve ser ilimitado de cada pessoa, como se o Pai apenas fosse capaz de entender através do Filho ${ }^{9}$. Por isso, Anselmo prefere dizer que Deus, como um todo, realiza cada uma e todas estas operações, o que significa que cada uma das pessoas é capaz de realizar todas estas operações. Anselmo prepara o terreno para esta afirmação em M 58, ao defender que tanto o Filho como o Espírito Santo são a mesma substância, sabedoria e virtude que o Pai. Mas, se assim é, então o que é dito do Pai deve ser dito do Filho e do Espírito Santo, do mesmo modo que a substância, sabedoria e virtude são a mesma. Aplicando este princípio à imagem psicológica (M 59), temos que Deus "compreende a sua memória como um todo, ama-a, como um todo recorda a sua inteligência, ama-a, e recorda o seu amor como um todo, e como um todo, compreende-o"10. Anselmo conclui (M 60) que nenhuma das pessoas precisa das outras para realizar estas operações e, por isso, cada pessoa é "essencialmente memória e inteligência e amor"11. Sintetizando:

(i) Pai $=$ Memória; Filho = Inteligência; Espírito Santo = Amor (M 59)

(ii) As três pessoas são a mesma substância, virtude e sabedoria (M 58)

$\therefore \quad$ (iii) Cada uma das pessoas é essencialmente memória, inteligência e amor (M 60)

É precisamente (iii) que Kilwardby rejeita. O problema é que Anselmo afirma que o Pai é memória mas também amor e inteligência (e o Filho inteligência mas também amor e memória; e o Espírito Santo amor mas também memória e inteligência) e ao mesmo tempo afirma que o Pai não é o mesmo que o Filho (isto é, não é inteligência) porque o Filho é gerado e o Pai não é gerado mas aquele que gera ${ }^{12}$. Kilwardby identifica o problema da conclusão errada de Anselmo em (ii), uma vez que ele entende que Anselmo estende o princípio da comunicabilidade da essência divina em demasia, sobrepondo-o ao princípio da distinção pessoal e, ao fazê-lo, destrói o critério essencial para manter a trindade de pessoas divinas. A dificuldade é evidente: Anselmo afirma que cada pessoa cor-

9 QLIS 36, 99.211-8.

10 "Totam quippe suam memoriam summus spiritus intelligat et amat, et totius intelligentiae meminit et totam amat, et totius amoris meminit et totum intelligit", $\mathrm{Mo}$ nologion, p. 70. Esta mesma concepção encontra-se já em Agostinho, DT 10.11.18.

11 "Singulus enim quisque essentialiter est et memoria et intelligentia et amor et quidquid summae essentiae necesse est inesse", Monologion, c. 60, p. 71.

12 QLIS 36, 102.295-304. 
responde na imagem psicológica da alma racional a uma faculdade mas que cada uma das faculdades é capaz de executar as operações que são próprias das outras faculdades/pessoas ${ }^{13}$. E Kilwardby entende que isso põe em causa a distinção entre pessoas ${ }^{14}$.

Anselmo ele mesmo reconhece o problema (M 61) ${ }^{15}$ e lida com ele fazendo corresponder a cada pessoa uma faculdade e que as outras pessoas são a mesma faculdade mas sem a operação; isto é, o Pai é a memória, cuja propriedade é gerar, enquanto que o Filho e o Espírito Santo são a memória que não gera ${ }^{16}$. Kilwardby mantém que a solução de Anselmo não responde ao problema, visto que o que as pessoas têm em comum não é a memória ou a inteligência ou o amor, mas a essência.

$\mathrm{O}$ argumento de Kilwardby é claro: se aquilo que distingue cada pessoa (e cada faculdade) é a sua propriedade pessoal (as suas operações), ao sustentarmos que cada uma das pessoas é essencialmente todas as faculdades, isto é, tem todas as mesmas propriedades das outras pessoas, então, as três pessoas não se distinguem e não podemos defender a existência da Trindade ${ }^{17}$. De outro modo, para Kilwardby, Anselmo não pode defender ao mesmo tempo (iii) e (i), porque em (i) Anselmo defende que cada uma das pessoas é essencialmente memória ou inteligência ou amor e em (iii) defende que cada uma das pessoas é memória $e$ inteligência $e$ amor. Kilwardby responde que Anselmo avança da predicação in recto à predicação in obliquo, isto é, da propriedade (neste caso, gerar) ser dita da pessoa (neste caso, o Pai) para a propriedade ser dita da essência (uma vez que o Pai também é essência). De outro modo, ao defender que

o Pai (/memória) gera

o Pai (/memória) é essência divina

Ergo, a divina essência gera ${ }^{18}$

13 QLIS 36, 102.309-14. Cf. Agostinho, DT 10.11.18.

14 QLIS 36, 102.300-4.

15 "Verum haec quaestio non difficile solvitur, si ea quae iam ratione inventa sunt considerentur", Monologion, p. 71. O argumento ocupa o resto do capítulo 61.

16 "Ad primam respondet Anselmus Monologio 61 quod est memoria gignens et memoria non gignens. Et memoria gignens Pater est, sed memoria non gignens est etiam Filius et Spiritus communis. Similiter est intelligentia genita et haec est Filius tantum, et est intelligentia non genita et haec est communis Patri et Spiritui. Similiter est amor procedens et non procedens, et prior solus est Spiritus Sanctus, secundus ad alias personas pertinet", QLIS 36, 101.283-6.

17 QLIS 36, 103.342-58.

18 "Istud enim non valet: Pater est generans et Pater est divina essentia. Ergo divina essentia generat. (...) Similiter cum dicitur: Memoria generat vel potius est generativa. Sed memoria est divina essentia. Ergo divina essentia generat vel est generativa. Et eodem modo de intelligentia et amore dicendum et de consimilibus", QLIS 36.8, 103.342-344 (...) 348-351. 
Anselmo comete a falácia figura dictionis, uma vez que toma a memória (/Pai) como geradora pela memória (/Pai) como essência. Ao fazê-lo procede a uma mudança de categoria, de relação para substância (na primeira acepção supponit pro relativo, na segunda pro substantia), relativamente àquilo que é o referente do termo ('memória'/'Pai') ${ }^{19}$. Embora o Pai (/memória) seja in re o mesmo que a essência divina, Ele é Pai (/memória) através de uma distinção conceptual ou modal relativamente a essa mesma essência ${ }^{20}$. Não se pode concluir pelo facto do Pai ser essência que todas as suas propriedades são propriedades da essência. O Pai (/memória) é essência considerado como id quod est, mas é também aquele que gera, relativamente àquilo que é gerado ${ }^{21}$, e a propriedade da ingeneratio ou innascibilitas convém apenas a Ele ${ }^{22}$. De outro modo poderíamos cair no absurdo de defender que a memória gera a inteligência; mas, se a memória é a inteligência, então a inteligência gera a inteligência ${ }^{23}$.

Um outro argumento, de natureza semântica, encontra-se nos nomes que podem ser predicados de Deus e das pessoas divinas. De acordo com

19 QLIS 36, 103.355-8. Na primeira proposição a categoria é relação e não acção porque em Deus gerar é aliquo modo esse vel se habere ad aliquid (QLIS 36.8, 110.571-572) - admitir algo diferente significaria admitir mudança em Deus. Kilwardby acusa frequentemente as posições que opõe de cometer a falácia figura dictionis: cf. NSLP 7, 40.19-20; Notulae super librum Elenchorum Aristotelis, apud S. Ebbesen, “The Ars Nova...”, pp. 347-48, n.58; QLIS 74, 234.96-98; In his QLIIS 148, 406.81-83 (cf. Aristotle, Sophistici Elenchi, 22, 178a 31-8); QLIII1S 8, 41-42.166-168; QLIIIIS 13, 64.43-45. D43Q 16, 23.440-47; 24, 474-75 (a lista não é exaustiva). Exemplos semelhantes aos que Kilwardby apresenta em D43Q 16 podem ser encontrados na obra Dialectica Monacensis, ed. L. M. de Rijk, in Logica Modernorum. A Contribution to the History of Early Terministic Logic. Assen 1967, pp. 579-80). Sobre esta falácia, ver C. L. Hamblin, Fallacies. Londres, 1970; S. G. Schreiber, Aristotle on False Reasoning. Language and the World in the Sophistical Refutations. Nova Iorque, 2003, pp. 38-40, 42; E. Krabbe, "Who is Afraid of Figure of Speech", Argumentation 12 (1998), 281-94; S. Ebbesen, Commentators and commentaries on Aristotle's Sophistici elenchi: a study of post-Aristotelian ancient and medieval writings on fallacies. Leiden, 1981.

20 "... distinctio facta circa memoriam non est distinctio rerum, sed rationum vel modorum circa rem eadem", QLIS 36, 102.315-6; e QLIS 36, 103.324-7. Ver também QLIS 36, 108.501-06: "Quamvis enim divina natura sit indistincta per res, multa tamen est in illa rationum distinctio. Et licet divina essentia in quantum talis non sit in se distincta, tamen adnexam vel cointellectam rationum distinctionem, quibus se communicat diversos hypostasibus, et secundum diversos modos originis. Et quia haec omnia idem sunt in re quod divina substantia, possunt per illam intellectam intelligi omnia".

21 QLIS 36, 103.351-3.

22 "Item ingeneratio vel innascibilitas soli Patri convenit", QLIS 36, 116.751.

23 "Memoria gignit intelligentiam. Sed memoria est intelligentia. Ergo intelligentia gignit intelligentiam", QLIS 36, 118.822-4. 
Kilwardby temos os seguintes tipos de nomes: os nomes pessoais (nomina personalia ${ }^{24}$ que se subdividem em nomes de primeira intenção, tais como 'Pai' (Pater), 'Filho' (Filius), 'Espírito Santo' (Spiritus Sanctus); e nomes de segunda intenção, como 'pessoa' (persona), 'hipóstase' (hypostasis), etc. ${ }^{25}$ Existem ainda os nomes concretos, tais como 'aquele que gera' (generans), 'aquele que nasce' (natus) ${ }^{26}$, 'aquele que procede' (procedens); e os nomes abstractos, tais como 'geração' (generatio), 'nascimento' (nativitas), 'processão' (processio) ${ }^{27}$. Também relativamente à essência - o que é comum às três pessoas - se podem utilizar nomes concretos, como 'Deus' e nomes abstractos, como 'divindade' (deitas); e ainda nomes de primeira intenção, como 'sapientia', 'bonitas' e nomes de segunda intenção ${ }^{28}$.

Centremo-nos nos nomes concretos. Kilwardby distingue, num nome concreto, um significado principal, que é a forma pela qual o nome é imposto (forma a qua nomen est imponitur) e um secundário, aquilo ao qual o nome é imposto (cui nomen est imponitur) ${ }^{29}$. (Kilwardby, como a maioria dos autores medievais, segue a concepção boeciana de que uma palavra (vox) torna-se significativa através de uma acto voluntário de imposição de um significado a uma coisa.) Kilwardby distingue assim entre o significado propriamente dito - a forma, essencial ou acidental - e o objecto de referência (o suppositum). O primeiro tipo corresponde a uma predicação in recto, o segundo a uma predicação in obliquo. Assim, ser humano (homo) significa a natureza humana ou humanidade (humanitas) in obliquo ${ }^{30}$.

Kilwardby prossegue o argumento dizendo que dois termos podem divergir quanto à significação primária mas concordar no que diz respeito à significação secundária. Tal é o caso dos termos 'Deus' e 'ser humano' que têm significados distintos mas que, no caso de Cristo, concordam quanto ao suppositum ${ }^{31}$. (O suppositum é o verdadeiro fundamento da predicação uma vez que é o sujeito ao qual algo é atribuído ou cuja atribuição é negada.) $)^{32} \mathrm{O}$ mesmo princípio pode ser aplicado a Deus Trinitá-

24 "Nomina personalia sunt quorum significata ad personas pertinent", QLIS 85, 269.116-7.

25 QLIS 85, 268-9.114-6.

26 Literalmente, 'aquele que é nascido'.

27 QLIS 85, 269.118-21.

28 QLIS 85, 269.122-9.

29 QLIIIIS 16, 74.33-5.

30 QLIIIIS 16, 74.38.

31 QLIIIIS 16, 74.45-7.

32 QLIIIIS 16, 75.65-7. 
rio. Por tudo o que foi dito, o Pai não pode ser dito do Filho, nem o Filho do $\mathrm{Pai}^{33}$, nem a memória da inteligência porque, embora sendo consubstanciais (isto é, sendo o supósito o mesmo), cada uma das pessoas significa algo diferente das outras. A forma a qua nomen imponitur et quam primam significat é, no caso do Pai/memória, gerar, e no caso do Filho/ /inteligência, ser gerado.

Kilwardby, embora divergindo da conclusão Anselmiana, pensa que existe a necessidade de qualificar a distinção pessoal de modo a evitar qualquer possível objecção fundada na limitação do poder divino, através do argumento - que Anselmo expressa, e bem, - da dependência de cada pessoa relativamente a outra para a realização da operação que pertence essencialmente à outra (por exemplo, Deus Pai compreender apenas através de Deus Filho). Esta possível objecção funda-se, na verdade, na possibilidade de se estender em demasia o princípio da distinção pessoal, centrando a discussão Trinitária naquilo que distingue as pessoas e esquecendo aquilo que as identifica. Kilwardby tenta oferecer uma solução para esta dificuldade e acredita tê-la encontrado com a distinção entre a propriedade pessoal ser primariamente dita da pessoa (e assim causa da distinção pessoal) e secundariamente da essência (permitindo manter a identidade de essência). Ou seja, tudo aquilo que é dito de cada pessoa é dito de Deus como um todo, mas per se da pessoa e acidentalmente da essência; por outro lado, tudo aquilo que é dito de Deus como um todo aplica-se igualmente a todas as pessoas. Assim,

(i) o Pai é essencialmente memória, mas acidentalmente inteligência e amor

(ii) o Filho é essencialmente inteligência, mas acidentalmente memória e amor

(iii) o Espírito Santo é essencialmente amor, mas acidentalmente memória e inteligência ${ }^{34}$

Kilwardby precisa a tese de Anselmo com a tese de Agostinho: amor (/vontade), memória e inteligência são uma só vida, uma só mente e uma

33 "Et ideo quae dividunt communem naturam, numquam de se praedicantur, et ideo non dicitur Pater Filius nec est, sicut neque homo asinus vel Petrus Paulus", QLIII1S 16, 75.63-4.

34 "Patri ergo secundum talis est, essentialis est memoria, sed accidentalis intelligentia et amor. Similiter Filio unde talis est, essentialis est intelligentia, sed accidentalis memoria et amor. Et Spiritui Sancto essentialis est amor, et accidentalis est memoria et intelligentia”, QLIS 36, 103.335-339. Acidentalmente neste caso, Kilwardby faz notar, significa apenas que cada pessoa tem uma disposição para as outras faculdades (“... non quod ibi sit aliquid vere accidens vel accidentale ut in creaturis, sed quod rationes istae habeant quandam accidentalem habitudinem ad invicem", QLIS 36, 103.339-40). 
só substância (DT 10.11.18). Mas, quando Agostinho diz que a mente se recorda de si mesma, se compreende e se ama a si mesma (DT 14.7.9), ele está a falar da mente como um todo, isto é, do ponto de vista da essência comum. Do ponto de vista de cada uma dessas operações - recordar, compreender, amar - elas correspondem a pessoas/faculdades distintas. Tal é a interpretação de Kilwardby relativamente ao texto de Agostinho e, na verdade, a continuação do texto parece dar-lhe razão (DT 14.7.9-12.22).

Para Kilwardby cada faculdade é responsável por operações que são suas em exclusividade mas que, na medida em que são operações da alma, se pode dizer que acidentalmente a faculdade, por exemplo, da memória executa as operações de entender e de amar. De outro modo, cada faculdade executa as operações próprias das outras faculdades em virtude da comunicabilidade da essência - isto é, de todas as três faculdades como as três pessoas serem uma só do ponto de vista da essência. O modelo psicológico parece resistir à comparação com a Trindade de que é imagem.

\section{Pensamos como falamos?}

Na mesma questão 36 (QLIS), Kilwardby levanta um outro problema relativo a este modelo psicológico, a saber, a questão da identificação do verbum com Deus Filho. Para autores como Kilwardby que se situam na confluência dos pensamentos de Agostinho e Aristóteles, é necessário conciliar os conceitos de verbum mentis e species intelligibilis na descrição do processo de conhecimento intelectual. Claude Panaccio coloca em termos muito precisos as dificuldades destes autores: enquanto que o verbum em Agostinho é o resultado de um acto do pensamento e nasce de um conhecimento prévio, em Aristóteles a species é depositada no intelecto passivo e consiste na aquisição de um conhecimento anteriormente não possuído ${ }^{35}$. Entre os vários modos de responder a este problema, uma das possibilidades é de identificar o verbum com a species e entendê-lo como o resultado do processo ${ }^{36}$; outra em tomar a species como ponto de

35 "Remember that the verbum mentis for Augustine springs out of an already possessed intellectual knowledge, while the Aristotelian process, on the contrary, is supposed to explain the original acquisition of intellectual knowledge. Moreover, while the intelligible species in the Aristotelian scheme, once it is impressed upon the possible intellect, stays there as habitual knowledge, the Augustinian verbum, on the other hand, occurs only in the process of conscious thinking, as the actual and transient - product of cogitation", Claude Panaccio, "From Mental Word to Mental Language", Philosophical Topics 20:2 (1992), 127.

36 Como por exemplo o faz Boaventura, Commentaria in Liber II Sententiarum, in Opera Theologica Selecta, ed. PP. Collegium S. Bonaventurae. Quaracchi, 1938, d.10, a.3, q.1; e Itinerarii mentis in Deum, ed. PP. Collegium S. Bonaventurae, in Opera omnia, V. Quaracchi, 1891, cap. 3, 5, p. 305: "Nam ex memoria oritur inte- 
partida e o verbum como, ou o processo em si ou o resultado desse processo (Kilwardby situa-se aqui); outra ainda em entender a species como um primeiro resultado do processo e o verbum como um segundo (esta é a solução de Tomás de Aquino) $)^{37}$.

O que me interessa aqui é entender a utilização do verbum mentis no contexto teológico, deixando por isso de fora deste artigo as considerações sobre se o pensamento é essencialmente linguístico bem como os aspectos mais estritamente ligados a questões de filosofia da linguagem, teorizadas por Kilwardby sobretudo no seu In Priscianus minor ${ }^{38}$. O meu interesse reside, assim, no modo como a analogia com a linguagem é entendida no contexto da discussão trinitária o que é, aliás, o contexto originário da discussão em Agostinho e Anselmo.

Se é certo que Kilwardby aceita a descrição de pensar (intelligere) como ver (videre), ele levanta algumas dúvidas relativamente à descrição Anselmiana (M 63) de pensar como falar (dicere) ${ }^{39}$, sobretudo pela comparação com o dizer corpóreo ${ }^{40}$. Kilwardby apresenta uma distinção entre

ligentia ut ipsius proles, quia nunc intelligimus, cum similitudo, quae est in memoria, resultat in acie intellectus, quae nihil aliud est quam verbum".

37 Tomás de Aquino, De veritate, ed. R. M. Spiazzi, in Quaestiones disputatae, 2. Turin: Marietti, 1964, 4.2. Para análise e referências, ver o artigo de C. Panaccio, "From Mental..." (especialmente páginas 127-9). Em Tomás de Aquino é necessário distinguir entre a palavra mental e o conceito uma vez que o conceito resulta de uma reflexão do intelecto sobre os seus próprios actos, isto é, tendo o verbum mentis como objecto. Ver Joshua P. Hochschild, "Does Mental Language Imply Mental Representationalism? The Case of Aquinas' Verbum Mentis", Proceedings of the Society for Medieval Logic and Metaphysics 4 (2004), 12-7.

38 Sobre a teoria da linguagem de Kilwardby, ver (organizado por ordem de relevância): I. Rosier, La parole comme acte. Sur la grammaire et la sémantique au XIIIe siècle. Paris, 1994; P.O. Lewry, "Robert Kilwardby's Commentary on De Accentibus", Mediaeval Studies 50 (1988), 119-121; Mary Sirridge, "Robert Kilwardby as a 'scientific grammarian'", Histoire Epistémologie Langage 10:1 (1988), 07-28; Idem, "'Instituitiones Grammaticae' XVII.187: Three Reactions", in I. Rosier (ed), L'Héritage des grammariens latins de l'antiquité aux lumières. Paris, 1988, pp. 171-229; Idem, "Robert Kilwardby: Figurative constructions and the limits of grammar", De ortu grammaticae. Studies in Medieval Grammar and Linguistic Theory in Memory of Jan Pinborg. G.L. Bursill-Hall, S. Ebbesen, K. Koerner (eds). Amsterdão-Filadélfia, 1990, pp. 321-337; H.A.G. Braakhuis, "Kilwardby versus Bacon? The contribution to the discussion on Univocal Signification of Beings and Non-beings Found in a Sophism Attributed to Robert Kilwardby", in E.P. Bos (ed), Medieval Semantics and Metaphysics. Studies dedicated to L.M. de Rijk. Nijmegen, 1985, pp. 112-42.

39 "Set ista responsio dubilabilis est, primo de hoc quod supponit idem esse dicere in divinis et intelligere", QLIS 36, 104.372-3.

40 "Item si dicere et intelligere sive videre in mente intelliguntur ad similitudinem eorum quae extra corporaliter geruntur, cum extra locutio sit quaedam actio et auditio sit passio ei respondens, erit similiter in mente locutio quasi actio et auditio quasi passio ei respondens”, QLIS 36, 104.380-3. 
duas formas de falar (loquere): per se et absolute, que corresponde à linguagem mental (isto é, o discurso interior que corresponde ao pensamento, cogitatio); outra, ligada à sua manifestação exterior, de modo a transmitir/expressar informação ${ }^{41}$. Dizer, nesta segunda acepção, implica, antes de mais a existência de quem diz e quem ouve, o que significa que se queremos manter a analogia do pensar com o dizer à luz do dizer corpóreo, temos de aceitar que também na locutio in mente existe (quasi) a acção de dizer e a paixão de ouvir ${ }^{42}$. Implica também a existência do que é dito, que por sua vez implica sempre a referência a algo, uma vez que a palavra, sendo significativa, é signo de algo para além de si ${ }^{43}$. Tal concepção, que se encontra em Agostinho (e parcialmente em Boécio), sendo desenvolvida por Abelardo, funda-se numa dupla função da linguagem: a palavra é um signo capaz de gerar um acto do entendimento e de capaz de designar a realidade exterior de que é signo ${ }^{44}$. A palavra falada (verbo coporali) é uma combinação artificial de sons de modo a causar uma afectação nos órgãos dos sentidos, e tem de ser, tal como qualquer espécie sensível, a 'fazer conhecer' o que é pensado ${ }^{45}$. Tal corresponde à acepção proprie do dizer, segundo a qual dizer consiste em expressar a similitudo de modo a fazer conhecer aquilo de que é similitudo ${ }^{46}$. A expressão dessa similitudo pertence apenas ao Pai (ad solum Patrem perti$n e n s)^{47}$, porque o dizer é propriedade exclusiva (notionale et personale) do Pai. Se dizer fosse comum a todas as pessoas não seria a propriedade pessoal de nenhuma ${ }^{48}$. Mas aquilo que é dito, por exclusão de partes - o

41 "Solutio. Est loqui dupliciter, vel in se et absolute apud ipsum dicentem et haec est cogitatio, vel relatum ad alterum secundum quod est manifestatum et sic superaddit aliquid super cognitionem", QLIS 56, 162.23-25. A origem desta distinção encontra-se, provavelmente, em Agostinho (DT 10.11.18).

42 QLIS 36, 104.380-4.

43 QLIS 36, 104.378.

44 A. Maierù, Terminologia logica della tarda scolastica. Roma: Edizioni dell'Ateneo, 1972, pp. 69-70.

45 "Verbum enim corporale proprie est vox litterata articulata expressa per instrumenta vocalia ad passionem animi notificandam", QLIS 36, 106.448-450; See also DOS XLVII.425, 148.18-20: "Item sermo sermo sensibilis est quia offert se sensui aliud derelinquens intellectui sicut alia signa sensibilia". Como signo potentíssimo (signum potentissimum), a palavra direcciona a alma daquele que é afectado por ela para a coisa de que ela (palavra) é signo (DOS XLVII.442, 153.08-13). Cf. E.J. Ashworth, "Signification and Modes of Signifying in Thirteenth-Century Logic: A Preface to Aquinas on Analogy", Medieval Philosophy and Theology 1 (1991), [39-67] 44.

46 "Proprie loqui vel dicere est idem quod similitudinem de se exprimere ad rei cuius est similitudo notitiam faciendam", QLIS 36, 106.432-4.

47 QLIS 36, 106.436-44.

48 "Item si dicere conveniret omnibus personis, tunc esset essentiale praedicatum et 
que aqui significa por exclusão de propriedades pessoais - não pode ser o Pai, porque o Pai é o que diz, não o que é dito. Aquilo que é dito é a essência divina, comum a todas as pessoas divinas ${ }^{49}$.

Resolvido o problema da atribuição, na analogia do pensar com o dizer corpóreo, de quem diz e do que é dito, falta apenas encontrar quem ouve. Ora, se à luz das propriedades pessoais aceites, o Pai gera o Filho, o que o Filho significa é ser gerado. Que o verbum é gerado não está em causa $^{50}$; o que é preciso é entender exactamente o que é gerado. Kilwardby entende ser necessário distinguir entre dois aspectos do verbum ${ }^{51}$ : por um lado, o verbum mentis é aquilo que é dito - e isso é, como vimos, a essência divina; por outro lado, verbum mentis é o pensamento (cogitatio) gerado a partir do conhecimento (notitia), guardado na memória, da similitudo da coisa (a essência divina) ${ }^{52}$, de modo a tornar conhecido ( $\mathrm{ad}$ indicationem) esse mesmo conhecimento ${ }^{53}$. Dizer que o verbum enquanto Filho é gerado pelo Pai significa dizer que a faculdade da memória gera a inteligência, e que ouvir significa aqui um acto de pensamento pelo qual a mente pensa actualmente nos seus conteúdos cognitivos. Isto é, a inteligência ouve. Embora ambos concorram para um mesmo acto de cognição ${ }^{54}$, fazem-no por relações opostas: o Pai diz, o Filho ouve. Anselmo está, deste modo, errado quando confunde as operações realizadas por faculdades distintas: compete à memória dizer e à inteligência ouvir, isto é, a memória apresenta a imagem do objecto e a inteligência compreende; e não, como ele propõe, que dizer é pensar interiormente ${ }^{55}$. Kilwardby

absolutum absque proprietate personali. Sed secundum Augustinum opposito modo se habet", QLIS 36, 105.403-5.

49 “... et rei cuius est verbum notificationem passionem (...) pertinet ad omnes personas”, QLIS 36, 107.461-2. Ver também QLIS 36, 109.517-22.

50 "Unde verbum universaliter genitum est, sed non omne genitum verbum est; loquimur enim modo de verbo mentali", QLIS 38, 122.16-8.

51 "Et hoc est proprie dictum verbum mentis, in quo duo attende, formationem scilicet cogitationis de notitia, quod est cogitatio passio pertinens ad solum Filium, et rei cuius est verbum notificationem passionem, quod pertinet ad omnes personas", QLIS 36, 107.459-62.

52 "Unde verbum secundum plenam descriptionem est similitudo de re expressa ad eius notitiam faciendam. Sic igitur proprie dicitur et pertinet ad solum Filium", QLIS 36, 107.462-4.

53 "... verbum autem quod de notitia memoriae gignitur ad indicationem eiusdem", QLIS 38, 122.24-5. Ver também QLIS 38, 123.44-5.

54 QLIS 36, 104-5.390-3. Agostinho defende que o verbum mental é gerado a partir da visão do que existe como conhecido na memória, sendo da mesma natureza desse conhecimento, tal como o Filho é gerado da substância do Pai (DT 15.11.20). Para Agostinho, a palavra (verbum) que falamos no nosso coração nasce do conhecimento guardado e apresentado pela faculdade da memória (DT 15.10.19).

55 "Videtur ergo locutio mentis pertinere ad memoriam proprie, et audire sive intelli- 
conclui que é impossível manter a analogia de pensar (intelligere/cogitando intueri) com dizer (dicere $)^{56}$, uma vez que tal colide com o princípio das propriedades pessoais ${ }^{57}$.

\section{Pensamos como vemos?}

A proposta do pensar como ver em Agostinho apenas se entende tendo presente a visão segundo o modelo teológico do homem exterior ${ }^{58}$, e não segundo o modelo fisiológico/naturalista da extra-missão dos raios visuais (DT 9.3.3 $)^{59}$. A trindade do homem exterior consiste no objecto exterior, na visão - isto é, o órgão dos sentidos informado pelo objecto que é percepcionado e a animi intentio que direcciona os sentidos para a percepção do objecto (DT 11.2.2.). A animi intentio é uma operação da mente, mais concretamente da faculdade da vontade ${ }^{60}$, que torna possível a visão (a'), que pertence ao nível da sensação e a visão (a'), que pertence ao nível do conhecimento intelectual ${ }^{61}$. De outro modo, pela visão (a') a alma dispõe da informação necessária para realizar a visão (a' "), que é pensar.

O paralelismo, bem como a continuidade, entre os dois tipos de visão é claramente formulado na seguinte passagem:

"Portanto, aquilo que um corpo num lugar é para o sentido corporal, isso mesmo é a imagem de um corpo na memória para o olhar do espírito; e aquilo que, quando se olha, é a visão para a forma daquele corpo a partir do qual o sentido é formado, isso mesmo, quando se pensa, é a visão para a imagem do corpo estabelecida na memória, a partir da qual é formado o olhar do espírito." 62

gere ad intelligentiam, et sic videntur ibi habere rationes oppositas. Et non videtur esse verum quod dicit Anselmus quod 'dicere sit cogitando intueri'”, QLIS 36, $104.386-9$

56 QLIS 36, 104.386-9. E QLIS 36, 106.425-6: “Aestimo secundum proprietatem loquendi et intelligendi quod non sint idem dicere et cogitando intueri vel intelligere".

57 "Ex his videtur quod dicere sit notionale et personale, et idem quod prius tunc sequetur scilicet quod non sit dicere idem quod intelligere", QLIS 36, 105.409-11.

58 Sobre o homem interior/exterior, ver Agostinho, DT 11.1.1.

59 Ver também De Genesi ad litteram, ed. J. Zycha, CSEL 28. Viena-Praga-Leipzig, 1894, 7.13.20.

60 Agostinho DT 11.2.5.

${ }^{61}$ Cf. DT 11.2.5; e 11.3.6. A cogitatio (o pensamento actual) é a unidade que resulta da conjugação (coactu) da trindade memória, visão interior e vontade.

62 Santo Agostinho, De trinitate/Trindade, trad. Arnaldo do Espírito Santo et al. Lisboa: Paulinas Editora, 2007, 11.4.7. 
Pensar como ver mental consiste no acto da alma olhar para dentro de si mesma, fechando-se aos sinais externos (DT 14.10.13). O actual pensar é assim descrito como a visão pela mente daquilo que é conhecido e guardado na memória. A palavra (verbum) é gerada por essa visão (DT 14.7.10). De facto, impõe-se a distinção entre o que é conhecido (e que permanece guardado na memória) e o que é actualmente pensado (DT $14.3 .5 ; 14.6 .8 ; 14.7 .9)^{63}$ : o conhecer não resulta da imagem apresentada pela memória, uma vez que essa imagem é em si conhecimento daquilo de que é imagem (aqui entra em jogo a definição Augustiniana de signo) ${ }^{64}$; mas pensar aquilo que é conhecido. Essa apresentação talvez seja melhor definida como presentificação, uma vez que o que a memória faz é tornar o objecto presente ao olho da mente.

Kilwardby concorda com Agostinho em que o acto de cognição intelectual se caracteriza por um ver mental (videre in mente); mais, ele considera que, na medida em que o processo de visão se caracteriza por uma forma de geração, o processo do ver mental parece funcionar de acordo com o modelo trinitário. Kilwardby entende que o mesmo pode ser dito do processo da percepção sensível. Aceitando o princípio que Aristóteles propõe no De generatione, que a alteração é uma forma de geração, o objecto sensível provoca via species uma alteração nos órgãos dos sentidos, de modo a gerar uma semelhança sua naquele que vê65. Como diz Aristóteles no terceiro livro do De anima, o sensível imprime a sua semelhança no órgão e assim gera o sentir em acto ${ }^{66}$. Deste modo parece que, segundo Aristóteles, a sensação em acto é uma certa alteração e que a alma sensitiva é alterada pelo objecto sensível ${ }^{67}$. Ora, diz Kilwardby,

63 "Multa enim intelligimus, secundum Augustinum De Trinitae X et XIV, quae non cogitamus", QLIII2S 60, 250.91-1 (DT 10.12.19; 14.6.9). Esta distinção corresponde, grosso modo, à distinção Aristotélica entre segunda potencialidade/primeira actualidade (o conhecimento de geometria) e o exercício desse conhecimento (segunda actualidade). Cf. Aristóteles, De anima II.5, 417a21-b2.

64 Para referências, ver Irène Rosier, La parole comme acte. Paris, 1994, pp. 96-7. Uma clara introdução à noção de signo no período medieval pode ser encontrada em Alfonso Maierù, “'Signum' dans la culture médiévale”, in Kluxen, Wolfgang et al (eds), Sprache und Erkenntnis im Mittelalter. (Miscellania Mediaevalia 13, I-II) Berlin-New York, 1981, vol. I, 51-72.

65 QLIS 35, 82-3.93-5.

66 De acordo com Kilwardby esta acção é violenta e não natural, na medida em que o princípio do movimento é exterior à coisa movida ("Quae enim recipiunt formam ab extrinseco agente solum, aut habent visum ad contrarium agentis, ut patet in forma impressionis corporalis et ibi est volentia", QLIIS 146, 402.69-71). Para referências relativas à definição aristotélica e kilwardbiana de movimento violento e natural, ver o meu "Robert Kilwardby on Celestial Motion", Mediaevalia Philosophica Polonorum 36.2 (2007), 90-119.

67 "Similiter in sentiendo ubi non est vere actus, ut dicit Aristoteles in III De anima, sensibile agens imprimit suam similitudinem in sensitivo et sic generat sentiens in 
"[a]lgo semelhante acontece no nosso intelecto pensante no qual não existe mudança. A memória tem em si mesma a coisa conhecida, ou a sua imagem (similitudinem) através da qual pode ser conhecida. O olho da mente não conhece o que é possível conhecer, excepto quando se volta para a memória e se aplica a ela, conhece ou pensa em acto, e isto porque a memória combinada com o olho [da mente] assimila a si o olho [da mente] imprimindo neste a imagem da coisa que tem em si mesma, não emitindo essa imagem mas uma semelhante àquela que possui, imprimindo esta no olho [da mente]. E esta imagem na memória que imprime e a imagem impressa no olho resulta na geração a partir da imagem impressa e do olho [da mente], que é a inteligência. E assim como na sensação a forma sensível permanece na sua matéria, após o que a sua imagem desaparece dos sentidos pelo voltar dos sentidos para outro objecto, e de novo é gerado por aquele o órgão em acto pelo tornar dos sentidos àquele, assim no intelecto a espécie inteligível permanece na memória, após o que a imagem impressa no olho [da mente] desaparece pelo voltar do olho [da mente] para outro objecto, e de novo a partir deste é gerada a inteligência pelo voltar do olho [da mente] para a imagem." 68

Nesta passagem Kilwardby compara a visão corpórea, na qual existe um objecto sensível (a ser) visto e um olho corpóreo, do mesmo modo que existe um objecto inteligível e o olho da mente que vê esse objecto

actu, quod est unum compositum ex sensitivo in potentia tamquam materia et specie sensibilis eidem impressa tamquam forma, et est sensibile in actu gignens sentiens genitum. Quod autem sentiens sit genitum vel sensitivum in actu quod est idem quod sentiens, patet secundum Aristotelem. Dicit enim in II De anima quod sensus in actu alteratio quaedam est. Ex patet quod sensitivum in actu sentiens est alteratum. Sed in De generatione docet quod alteratio est generatio quaedam et alteratum generatum quoddam. Quare patet quod sentiens sive sensitivum in actu est quoddam genitum", QILS 35, 84-5.152-61.

68 "Omnimo simile convenienter est in nostro intellectu cogitante ubi motus non est. Memoria enim habet rem cognoscibilem in se, vel eius similitudinem qua potest intelligi. Acies mentis nondum cogitans possibilis est cogitare vel intelligere, quae quando convertit se super memoriam et applicat se illi, intelligit vel cogitat in actu, et hoc quia memoria aciei coniuncta assimulat sibi aciem imprimendo ei rei similitudinem quam apud se tenet, non a se emittendo quam habet, sed similem illi quam habet, imprimendo illi scilicet aciei. Et est similitudo imprimens in memoria et similitudo impressa in acie, et fit unum genitum ex similitudine impressa et aciei, quod est intelligentia. Et sicut in sentiendo manet forma sensibilis in sua materia, postquam eius similitudo perit a sensu per aversionem sensus ad aliud sentiendum, et iterum generatur $\mathrm{ab}$ ea sensitivum in actu per conversionem sensus ad illam, sic in intellectu manet species intelligibilis in memoria, postquam similitudo quam impressit aciei perierit ab acie per conversionem aciei ad aliud cogitandum, et iterum ab illa generatur intelligentia per conversionem aciei ad illam", QILS 35, 85.162-76. Cf. Agostinho, De Trinitate 11.3.6. 
inteligível ${ }^{69}$. A memória tem em si a coisa cognoscível ou a sua semelhança (a espécie inteligível) pela qual a coisa é conhecida, mas esta apenas é pensada efectivamente (em acto) quando esta imagem é apresentada pela memória ao olho da mente, cujo acto é a inteligência. $\mathrm{O}$ olho da mente é informado pela imagem do objecto guardada e apresentada pela memória ${ }^{70}$, e esse olhar da mente para essa imagem é o actual pensar. A inteligência é assim gerada pela memória, como o Filho pelo Pai. Ao voltar-se para uma nova imagem, o olho da mente deixa essa imagem, isto é, deixa de ser informado por essa imagem que é guardada pela faculdade da memória de modo a eventualmente ser apresentada para um novo acto do pensamento/visão interior (o que corresponde ao que Agostinho diz no DT 11.3.6).

Para Kilwardby, na leitura que ele faz de Agostinho ${ }^{71}$, os olhos corpóreos vêem a coisa sensível através da sua espécie, enquanto que a visão intelectual/interior vê (interius cogitando) através da similitudo da espécie (non per ipsam speciem, sed per eius similitudinem) - isto é, através da imagem feita pela alma a partir da espécie recebida no órgão dos sentidos $^{72}$. Kilwardby pretende mostrar a distinção entre os dois tipos de visão: enquanto que a visão corpórea tem lugar na presença do objecto, a interius cogitando tem lugar na ausência do objecto e aquilo que é visto (= actualmente pensado) é a imagem do objecto guardado pela memória.

A atenção do olho da mente é exclusiva, ou seja, implica que o olho da mente apenas é informado por uma imagem apresentada pela memória a um dado momento, dedicando completamente a sua atenção a essa imagem que vê em si mesmo, e na exclusão de prestar atenção a outros objectos exteriores (DT 11.4.7). Contudo, esse mesmo ser humano cuja atenção da mente está centrada num determinado acto de pensar, continua a receber estímulos exteriores. No caso de Agostinho a questão é ainda mais complexa, uma vez que ele defende que a vontade opera na sensação e na intelecção. Mas, neste caso, como é possível à vontade estar presente a realizar um acto de pensar e ao mesmo tempo dirigir a atenção dos órgãos dos sentidos relativamente a objectos exteriores? Em DT 11.4.7, Agostinho parece afirmar que essa concentração da mente impede a atenção face aos objectos sensíveis.

É importante lembrarmos que, para além das semelhanças, Agostinho

69 A mesma ideia, embora com enfoque na acção iluminativa do sol e da lux spiritualis, encontra-se em Roberto Grossetesta. Cf. Steven P. Marrone, Light of Thy Countenance: Science and Knowledge of God in the Thirteenth Century. Leiden, 2001, pp. 46-7.

70 A memória como o ‘armazém' das imagens (cf. DT 15.12.22).

71 Cf. DT 14.3.5.

72 QLIII2S 22, 70.52-5. 
e Kilwardby têm teorias diversas sobre a natureza da alma humana. Agostinho defende (A) a identidade da alma com as suas faculdades, o que significa que as operações realizadas por uma faculdade são antes de mais operações da alma. A alma (B) é uma unidade indivisível, estando por isso ausentes da sua teoria da alma o problema da natureza das partes/formas/ /almas vegetativa, sensitiva e intelectiva do modelo Aristotélico ${ }^{73}$.

Para Kilwardby, a alma humana é uma substância espiritual, não simples, mas composta de partes essencialmente distintas: a alma humana é constituída por uma pluralidade de formas substanciais. Contudo, cada uma dessas formas ou essências ou potentiae, para usar a terminologia específica de Kilwardby, é constituída por faculdades que não são distintas da forma substancial. (A') A cada operação essencial corresponde uma faculdade distinta $^{74}$. No caso de operações que não dependem uma da outra e que podem ser separadas segundo o sujeito e o ser, tal como sentir e pensar, essas operações correspondem a uma diversidade de essências (ou formas substanciais ${ }^{75}$. (B') A alma humana é composta por três formas substanciais $^{76}$. Assim, a forma intelectiva é constituída pelas faculdades da memória, intelecto e vontade que são aspectos da mesma forma essência, do mesmo modo que as pessoas divinas são aspectos da mesma essência.

Enquanto Agostinho pode defender, seguindo (A), que a alma através de (a') forma uma imagem do objecto exterior e que a alma volta-se sobre si mesma, realizando (a"), e que, seguindo (B), é a mesma faculdade (vontade ou a intentio animi) responsável por dirigir a alma para o objecto afectando os sentidos e a imagem apresentada pela memória ao olho da mente (DT 11.4.7) ${ }^{77}$, Kilwardby necessita de recorrer a faculdades distintas porque defendendo (A') é necessário que a faculdade que

73 Ver, por exemplo, DT 10.11.18 ("uma vida, uma mente, e uma essência”). Agostinho não é, contudo, muito claro na formulação desta unidade o que tornou possível que os autores da tradição pluralista (das formas substanciais) o tenham utilizado como autoridade. Sobre esta discussão e o uso de Agostinho pelo movimento pluralista, ver Ricardo Zavalloni, Richard de Medievallia et la controverse sur la pluralité des formes. Louvain, 1951 (especialmente pp. 430-56).

74 "Quia per notitiam obiectorum et operationum venimus in notitiam potentiarum et habituum, secundum Philosophum”, QLIII2S 31, 121.178-80. Also: “...et novi a diversitate formarum diversitatem procedere accionum, et quia per diversitatem obiectorum venitur in cognicionem diversitatis accionum, et quia inde proceditur ad cognicionem diversitatis in potenciis et formis", E 7, 49.23-26.

75 QLIS 61, 175.63-9.

76 "Non ergo intelligatis de vegetativa, sensitiva et intellectiva tamquam de tribus accidentibus, sed tamquam de tribus formis substancialibus unum totum continentibus", E 5, 44.05-08. E, "Et sicut differencie tres se habent in una diffinicione, sic iste tres potencie vegetativa, sensitiva, intellectiva in una anime humane substancia.", E 5, 43.6-8.

77 Ver também DT 11.8.15. 
realiza (a') seja distinta da faculdade que realiza (a') porque, segundo (B') pertencem a formas substanciais distintas. Por outro lado, precisamente por defender (A') e (B'), Kilwardby não está sujeito às objecções que levantamos relativamente a Agostinho.

Mas está sujeito a outras. Ao interpretar o processo da sensação, como uma espécie de geração na qual o objecto sensível imprime espécie sensível no órgão dos sentidos e assim actualiza a potencialidade desses mesmos sentidos, isto é, de acordo com a tese de que o objecto gera (no sentido causal) a sensação, Kilwardby contradiz o que defende noutras obras. A concepção da visão corpórea e da visão intelectual como o resultado da acção do objecto sobre o órgão corpóreo e a faculdade está em claro contraste com a definição do processo de percepção sensível, tal como esta se encontra no DSF. Isto deve ser dito mesmo reconhecendo a natureza problemática de algumas passagens do DOS. (É contudo interessante a utilização de Aristóteles (De anima) no contexto da discussão trinitária ao lado de Agostinho (De trinitate) ${ }^{78}$, uma vez que constitui um bom exemplo - contra quem pretende ver em Kilwardby um conservador anti-Aristotélico - da vontade de Kilwardby de conciliar Aristóteles e Agostinho.)

No DSF Kilwardby descreve o processo da percepção sensível partindo do realismo epistemológico Aristotélico, mas limitando o papel do objecto à afectação dos órgãos dos sentidos ${ }^{79}$. A acção do objecto sensível (actio rei sensibilis) afectando o orgão dos sentidos é apenas a ocasião necessária, ou causa efficiens per accidens, da percepção ${ }^{80}$. A causa eficiente per se é a alma sensitiva e o processo da percepção tem uma natureza activa devido à natureza da alma que ele identifica como (in)tensional ${ }^{81}$, espiritual, indivisível e assimilativa/conformativa. Este último aspecto significa que a alma faz em si mesma, a partir da espécie sensível recebida no órgão dos sentidos, por assimilatio/conformatio, uma imagem do objecto através do qual o objecto é percepcionado ${ }^{82}$. De

78 S.F. Brown, "The Reception and Use of Aristotle's Works in the Commentaries on Book I of the Sentences by the Friar Preachers in the Early Years of Oxford University", in J. Marenbon (ed), Aristotle in Britain During the Middle Ages. Turnhout, 1996, pp. 357-8.

79 "Quod ergo dicit Aristotiles quod sensus est susceptiuus specierum sensibilium sine materia, de organo sensitiuo dicitur", DSF 112, 79-80.36-02.

80 "Similiter anima occurrens passionibus corporis per se causa cognicionis est, sensibilia et organum sensitiuum accidentalis sicut instrumentum uel instrumenta quibus uitur anima ad sui informacionem", DSF 123, 82.34-6.

81 "... attenta actio anime erga corpus, per quam et in qua formatur in illa ymago et conversio aciei in se, per quam et in quam sentitur ymago", DSF 125, 83.24-6.

82 "Item, in 6 De musica, capitulo I4, ubi declarat quomodo anima non patitur a corpore, set omnino facit in illo et de illo (...) Ex hiis omnibus constat Augustinum intedere quod spiritus sensitivus dum sentit non recipit ymagines sensibilium a corpore tanquam patiens ab agente", DSF 54, 67.6-16. E, "In quo, ut iam patet, 
acordo com Kilwardby, a memória é a parte inferior do espírito incorpóreo (est infimum spiritus incorporei), através do qual este espírito se conjuga/conecta (coniungat) com o espírito corpóreo ${ }^{83}$. Neste sentido esta faculdade é a primeira a reagir às transformações do espírito corpóreo, no processo de percepção sensível.

Kilwardby apresenta uma longa análise da faculdade da memória em QLIS 62. Antes de mais ele contrapõe as posições de Aristóteles e Agostinho sobre a memória. De seguida, ele analisa a relação entre memória e inteligência do ponto de vista da prioridade de operação. Aqui ele defende que a memória realiza duas operações, ter (habere et tenere, quod pro eodem reputo) e conservar (conservare). E quanto à primeira (ter), a memória precede a inteligência tanto do ponto de vista temporal como da natureza; quanto à segunda, a inteligência por vezes precede (a memória), uma vez que a obra da inteligência é julgar o que está conservado. A estas duas operações deve juntar-se ainda a de apresentar à memória as imagens dos objectos conhecidos.

Existe uma dupla faculdade da memória: uma que pertence à parte irracional da alma, com a qual comunicamos com os outros animais e que pode ser chamada de brutal ou irracional ${ }^{84}$; outra que pertence à parte racional da alma pela qual ultrapassamos os restantes animais ${ }^{85}$. A memória racional é, por sua vez, bipartida em superior e inferior, ou interior e exterior. A primeira diz respeito às coisas espirituais, conhecidas por visão intelectual e que não são adquiridas. A segunda contém imagens das coisas corporais adquiridas através dos sentidos e das quais é visão espiritual ou imaginativa ${ }^{86}$. Ou seja, existe no homem uma memória tripla, i.e. a supre-

patitur corpus ab alio corpore et non agit in spiritum, sed spiritus eius passioni occurrit agens", DSF 102, 77.02-3. Ao defender a sensação como uma forma de geração, Kilwardby assume uma tese distinta e dificilmente conciliável com esta. Uma análise detalhada deste processo pode ser encontrada nos meus dois estudos: "Robert Kilwardby on Sense Perception", in P. Kärkkäinen \& S. Knuuttila (eds), Theories of Perception in Medieval and Early Modern Philosophy. Dordrecht, 2008, pp. 87-99; "Robert Kilwardby on the Human Soul”, P. Thom e H. Lagerlund (eds). A Companion to Robert Kilwardby. Leiden (forthcoming).

83 "Memoria enim, quantum michi uidetur, est infimum spiritus incorporei quo coniungitur cum spiritu corporeo, quod et primum suscipit huiusmodi passiones a spiritu corporeo, et eas reddit in se conuerse", DSF 217, 108.18-21.

84 QLIS 62.1, 179.59-60; DSF 207; LSP 401.39-43.

85 "Ad huius evidentiam notandum quod duplex est memoria: Una quae pertinet ad partem animae irrationalem, quam etiam communicamus cum brutis, et potest vocari brutalis vel irrationalis. Alia quae pertinet ad partem rationalem, in qua excellimus bruta", QLIS 62, 179.55-58.

86 "Ut autem plenius eluceat natura memoriae, nota quod haec memoria posterior quae rationalis est, bipartida est scilicet superior et interior, vel inferior et exterior, quarum prima pertinet ad superiorem rationem, secunda ad inferiorem. Et prima continet spiritualia de quibus est visio intellectualis, quae per se ipsa sunt praesentia, et ut mul- 
ma que é da razão superior e a inferior que é da parte da alma sensitiva, e ainda a média que é da razão inferior. Destas, a suprema e a inferior são diversas tanto em natureza própria quanto em objecto, porque a suprema é de natureza racional e contém tanto imagens espirituais quanto inteligíveis. A inferior na realidade é de natureza irracional e contém apenas imagens das coisas corpóreas. A média concorda com a memória suprema em natureza, porque a razão superior e a inferior têm a mesma natureza (racional), mas diferem quanto à disposição ou objecto ${ }^{87}$. Por outro lado, (a média) difere da inferior quanto à natureza mas concorda com esta quanto ao objecto. Assim, contém imagens das coisas corpóreas representadas à inteligência inferior, assim como a memória contém estas e as exibe à visão daquela alma comum a nós e aos restantes animais.

Posto que a alma não conhece (intelligit) ao olhar fora de si para os objectos distantes, mas vê em si mesma aquilo que conhece (quod intelli$g i t)^{88}$, é necessário primeiramente que tenha a espécie cognoscível na memória, a qual é considerada pela inteligência através do olho da razão

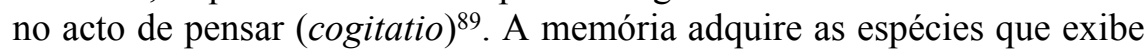
ao olho (da mente) por recepção, isto é, através da assimilação natural ${ }^{90}$. A memória brutal ou irracional assimila-se aos sentidos naturalmente in passione, enquanto a memória inferior racional assimila-se à parte sensitiva por esta conjugação natural. Assim a memória recebe através da assimilação daquilo com que naturalmente está conjugada/unida (QLIS 62). No caso da memória racional superior, ela possui os objectos inteligíveis em si mesma à partida.

tum perpetua. Secunda continet imagines rerum corporalium per sensus adquisitas de quibus est visio spiritualis sive imaginativa.", QLIS 62, 180.89-95.

87 "Et dico istas differentias quoad habitus, non quoad potentias forte.", QLIS 62, 180.104-5.

88 "In priori ergo memoria quam brutalem vocamus, nota quod illa naturaliter praecedit visionem interiorem animi, quae est ei loco intelligentiae. Cum enim animus in se intuetur speciem rei sibi affixam non exterius sentiendo, sed passionem a sensu intus derelictam contemplando, oportet quod illam habeat sibi exhibendam, antequam a se exhibitam respiciat. Unde prior est ibi memoria quae tenet et habet speciem, posterior vero visio", QLIS 62.1, 179.68-73.

89 "In altera vero memoria quae rationalis est, similiter patet quod illa prior est quam intelligentia. Non enim intelligit mens respiciendo extra se ad distans, sed in se videt quod intelligit, et loquor de immediato intellecto, et sibi exhibet speciem quam videat. Et ita oportet quod ibi prius habeatur et teneatur species cognoscibilis a memoria, quam ab acie rationis consideretur per intelligentiam.", QLIS 62.1, 179.80-4.

90 "Sed quaeris forte quomodo memoria habet speciem exhibendam aciei nisi recipiendo, et si recipiendo habet, quomodo aliter recipit quam videndo. Respondeo: Habet eam per receptionem. Sed haec receptio non fit videndo proprie, sed naturali assimulatione.", QLIS 62, 181.134-7; and QLIS 62, 181.142-3 "Sic ergo memoria recipit per assimulationem ad illud cui naturaliter copulatur". 
É exactamente essa imagem na memória que dá origem à visão interior do mesmo modo que é a espécie do objecto no órgão dos sentidos que dá origem à visão corpórea, tal como descrito no texto acima citado. A imagem (que é uma similitudo do objecto) que é emitida pela memória e que é impressa no olho da mente, diz Kilwardby, não é a mesma imagem que a memória possui, mas uma semelhante a esta (similem illi quam habet). A razão pela qual Kilwardby o diz é evidente e mostra que ele toma a sério a analogia que está a apresentar: da mesma forma que o objecto emite uma similitudo de si mesmo, mas não a sua forma (sensível), a memória não emite a forma (similitudo') que possui mas uma similitudo" dessa forma (que é a species intelligibilis). $\mathrm{O}$ olho da mente apenas compreende aquilo sobre o qual se aplica, a imagem apresentada/tornada presente pela memória, e a esse acto de cognição (actual) Kilwardby chama inteligência. O acto de visão mental é o acto pelo qual o intelecto conhece o objecto que lhe é apresentado pela faculdade da memória sob a forma de uma imagem produzida pela memória a partir da espécie que reside no seu interior. Do mesmo modo que a espécie sensível é emitida pelo objecto sob a acção de uma fonte de luz, em princípio o sol (um objecto apenas é visível se iluminado), a imagem que é impressa no olho da mente e que dá origem à visão intelectual é emitida pela acção da memória. (O problema é que ao fazê-lo, Kilwardby cria aqui uma outra representação que parece algo desnecessária e que levanta a séria dificuldade de perceber o que ela representa; isto é, a similitudo' da similitudo' é uma representação da similitudo' ou da coisa de que a similitudo' representa?)

Existe contudo um limite para a comparação entre a visão corpórea e a visão intelectual interior, que se funda na natureza da imagem e daquele que a về ${ }^{91}$. Na questão 38 do seu QLIS, Kilwardby analisa a relação entre imagem (imago) e palavra (verbum). O contexto da questão é se o nome a ser imposto ao Filho deve ser verbum ou imago, e em que sentido, os dois nomes se adequam à natureza do Filho como ser gerado (que, como tivemos oportunidade de discutir anteriormente, é a sua propriedade pessoal no seio da distinção Trinitária) ${ }^{92}$. Segundo o nosso Dominicano, a imagem é uma espécie de similitudo ${ }^{93}$, ou para ser mais preciso, a imagem é a imitação de algo quer esta imitação seja artificial (como uma pintura) ou natural, e neste caso, ou racional ou irracional - Kilwardby refere-se aqui

91 QLIS 35, 83.115-22.

92 "Deinde quaeritur specialiter de nominationibus Filii. Dicitur enim Filius imago, verbum. Quaeritur differentia istorum et quo congruentius nominetur in divinis persona genita", QLIS 38, 122.01-3.

93 "Ad primum quod imago imponitur a similitudine imitante. Similitudo enim per se paritatem importat similium, sed imago subauctoritatem unius similium ad reliquum", QLIS 38, 122.09-11. 
às imagens feitas pela alma, quer na parte sensitiva ou na parte intelecti$\mathrm{va}^{94}$. A imago pressupõe uma conformidade natural em que a imitação é causada por aquele do qual é imitação; por exemplo, as três faculdades da alma racional imitam as pessoas divinas; similitudo pressupõe uma conformidade de natureza entre imitação e imitado; por exemplo, a forma naturalis (a cor no medium) gera uma similitudo que é da mesma natureza da forma naturalis ${ }^{95}$. Aquilo que é visto gera (causalmente) uma similitudo de si naquele que về ${ }^{96}$, mas essa similitudo gerada é imperfeita relativamente àquilo de que é similitudo.

Mas a conformidade entre a imagem e aquilo de que é imagem é, no caso das coisas criadas, incompleta - a imperfeição das representações reside, para Kilwardby, na incapacidade de um poder finito criado (finito porque criado) de produzir como efeito algo superior a si mesmo como causa, isto é, o efeito de algo finito é ele mesmo finito e imperfeito ${ }^{97}$. A espécie sensível, produzida pela forma sensível do objecto, é uma imitação (/representação) incompleta e imperfeita da forma sensível que a gera. Ao afectar os órgãos dos sentidos, a espécie sensível produz um efeito que é incompleto e imperfeito em relação à forma sensível que o causa. A verdadeira imagem deve representar o modo de ser da coisa que representa; ora, apenas no caso de Deus, o Filho é imagem ou similitudo perfeita do Pai ${ }^{98}$.

Concluindo, Kilwardby aceita a analogia do pensar como ver mas refuta a analogia do pensar como falar porque entende que a natureza do pensar como processo se adapta melhor à descrição do ver como processo, em comparação à natureza do dizer que acentua o resultado - o resultado do pensar é o pensar em si, enquanto processo pelo qual se compre-

94 “... imago est quod aliud imitatur in assimulatione, sive sit artificiale, sive naturale, et hoc sive rationale, sive irrationale", QLIS 38, 122.23-4. Ver também QLIIS $77.3,211-212.28-38$.

95 QLIIS 77, 212.41-5.

96 QLIS 35, 83.96-9.

97 "Res autem causata est potentiae finitae et modicae in respectu, et ideo exprimit in causando sibi similem imaginem iuxta gradum suae potentiae", QLIS 89, 280.75-77; e QLIIS 77, 212.41-59: "Forma enim naturalis, ut facies in speculo vel color in medio, exprimit et gignit de se similitudinem suam. Et haec similitudo est imitatio naturalis illius et est eiusdem naturae cum forma de qua gignitur, non tamen ad plenum. (...) Similitudo autem est quaecumque convenientia formalis".

98 “... omnis imago repraesentare debet illud cuius est imago et quoad existentiam suam et quoad modum existentiae. Sic autem Filius repraesentat Patrem", QLIS $39,124.22-24$. Sobre a correspondência entre o conhecimento e aquilo que é conhecido em Agostinho, ver DT 9.11.16. No caso da mente e de Deus, o conhecimento de si mesmos significa uma perfeita semelhança entre o conhecimento e aquilo que é objecto desse conhecimento; o mesmo não se pode dizer do conhecimento a partir das semelhanças/imagens dos objectos sensíveis. 
ende o que se considera/contempla; enquanto o resultado do dizer faz corresponder à mesma faculdade a operação de ouvir e o ser a palavra dita. (Nesse sentido, diz Kilwardby, o ouvir está mais próximo do ver do que do dizer.) $)^{99} \mathrm{O}$ verbum é a cogitatio, que se realiza a partir das imagens guardadas e apresentadas pela memória, sobre o qual tanto Agostinho (DT 15.10.19) como Anselmo (M 62) concordam ${ }^{100}$. O que nasce do conhecimento guardado na memória é a inteligência, isto é, o olho da mente informado pela similitudo da espécie inteligível, actualmente pensando. $\mathrm{O}$ resultado é o processo porque o verbum (inteligência) é a cogitatio (acto do pensamento) que nasce do conhecimento (espécie inteligível) na memória: cogitatio est verbum natum de memoriae notitia similitudinem qua potest intelligi.) A memória é o principium cognitionis e a inteligência a sua consummatio ${ }^{101}$, do mesmo modo que o Pai é o princípio da geração e o Filho aquele que é gerado. O discurso mental, o dicere in mente é, assim, o actual pensar das imagens dos objectos guardadas na memória. Esta tese, claramente Augustiniana, é, para Kilwardby, mais precisa do que a proposta por Anselmo, uma vez que assenta nas propriedades mutuamente exclusivas das pessoas divinas.

\section{RESUMO}

No presente artigo analiso a leitura feita por Roberto Kilwardby das teorias de Agostinho e de Anselmo sobre o verbum mentis. O artigo está dividido em três secções. Na primeira, analiso como o critério de Kilwardby para a distinção pessoal na Trindade divina (por via de origem) é aplicado aos poderes da mente racional. Kilwardby considera a compreensão anselmiana da solução de Agostinho, incapaz de suportar a distinção real das pessoas. Nas duas restantes secções, ocupo-me dos dois modelos do pensar: o pensamento como fala (secção dois) e o pensamento como visão (seç̧ão três). Defende-se aqui que Kilwardby aceita o modelo da visão e rejeita o modelo da fala.

99 QLIS 36, 104.383-4.

100 "Verbum enim secundum Augustinum De Trinitate 1. XV c. 24 est 'cogitatio formata de notitia memoriae'. Et Anselmus Monologio 48 idem dicit”, QLIS 36, 107.457-9.

101 QLIS 36, 103.328-9. 


\begin{abstract}
In the present article I examine Robert Kilwardby's reading of Augustine's and Anselm's theories of the verbum mentis. The article is divided into three sections. In the first, I examine how Kilwardby's criterion for personal distinction within the divine Trinity (by way of origin) is applied to the powers of the rational soul. Kilwardby considers Anselm's understanding of the Augustinian solution unable to support the real distinction of persons. In the two remaining sections, I inspect the two models of thinking: thinking as speaking (section two) and thinking as seeing (section three). It will be argued that Kilwardby accepts the seeing model and rejects the speaking model.
\end{abstract}

